\title{
A Group Contribution Model for Prediction of the Viscosity with Temperature Dependency for Fluorine-Containing Ionic Liquids
}

\author{
Mehdi Sattari, *, ${ }^{a, b}$ Arash Kamari, ${ }^{a}$ Hamed Hashemi, ${ }^{a}$ Amir H. Mohammadi, ${ }^{a, c}$ Deresh \\ Ramjugernath, $\dot{\dot{\prime}}, a$
}

${ }^{a}$ Thermodynamics Research Unit, School of Engineering, University of KwaZulu-Natal, Howard College Campus, King George V Avenue, Durban 4041, South Africa

${ }^{b}$ Department of Chemical Engineering, Buinzahra Branch, Islamic Azad University, Buinzahra, Iran

${ }^{c}$ Institut de Recherche en Génie Chimique et Pétrolier (IRGCP), Paris Cedex, France

\begin{abstract}
One of the barriers against application of ionic liquids (ILs) for industrial separations is their relatively high viscosity. The viscosity of the IL can however be decreased by inserting the fluorinated moieties into the anion structure. Hence, if one could find a relationship between chemical structure, temperature, and viscosity one could design fluorine-containing ILs (F-ILs) with desired specifications. In this communication, two extensive dataset of F-ILs were gathered; one with reliable sources consisting of 863 experimental viscosities for 85 F-ILs, and the other including unreliable sources consisting of 1160 experimental data points for 332 F-ILs. Using the reliable dataset an efficient group contribution (GC) model was developed, which employs a total of 35 functional groups to estimate the temperature-dependent viscosities of FILs. The proposed GC model produced a low average absolute relative deviation (AARD) of $3.23 \%$, root-mean-square error (RMSE) of 0.19 , and coefficient of determination $\left(\mathrm{R}^{2}\right)$ of 0.977 . The other model developed using the second database only parameterized in supplementary materials.
\end{abstract}

Keywords: Group Contribution; GC; Viscosity; Fluorine; Ionic Liquid.

\footnotetext{
* Corresponding author, Email: mehdi.sattari@gmail.com

${ }^{\dagger}$ Corresponding author, Email: ramjuger@ukzn.ac.za
} 


\section{Introduction}

Over the last few decades, numerous studies have undertaken on ionic liquids (ILs) and their potential use in various industrial applications has been demonstrated by several researchers. Their generally low melting point of below $100{ }^{\circ} \mathrm{C}$ is one of the most important properties of ILs, which are often hydrolytically stable. Ionic liquids are typically composed of a large organic cation and an anion of inorganic or organic compounds and are generally liquid at or near room temperature (typically below $100{ }^{\circ} \mathrm{C}$ ) [1-4].

Generally, ionic liquids have some significant properties compared with common organic solvents such as higher thermal stability, extremely lower vapor pressures and thus negligible volatility, which make them desirable as potential solvents [3, 5-7]. Due to these properties, ILs have numerous potential applications, such as in extraction and separation processes [8-10], lubricants [11-14], waste recycling [15-18], catalysis [19, 20], gas separation and $\mathrm{CO}_{2}$ capturing [21-25], and many more [26-33].

One of the barriers against replacing commonly used solvents with ionic liquids in various applications is the relatively high viscosity $(\eta)$ of ILs which results in low diffusion coefficients, slow mass transfer, and low electrical conductivity $[34,35]$. Therefore, research has to be undertaken to synthesize ILs with low viscosity and low melting points. Initial investigations have shown that the insertion of fluorinated moieties into the molecular structure of ionic liquids could result in reduction of viscosity as well as the melting point of ILs [2, 34, 36-38]. 
ILs consist of ions, viz. a cation and an anion. In theory the cation and anion can be selected to have molecules with desired properties for a particular application. As such, ILs have been termed as "tunable" and "designable" materials [39]. Consequently, the values of viscosity can be tuned by selecting appropriate combinations of ions, especially fluorine-containing ions. The process of selection can be sped up by using a predictive model which has the ability to correlate the viscosity data based on chemical structure of ions or other thermophysical properties.

Abbott [40] recommended the application of hole theory for the definition of the viscosity of ILs and molecular liquids. Despite the introduction of this theory for the estimation of viscosity, the model did not produce satisfactory predictions for ILs and had a percentage average absolute relative deviation (AARD\%) of 122\%. Bandres et al. [41] predicted the viscosity of 8 pyridinium ionic liquids by modifying the hole theory suggested by Abbott [40]. They introduced an efficient IL radius $\left(R^{*}\right)$ to improve the estimations. The $R^{*}$ was fitted to real/laboratory viscosity data points at a pressure of $0.1 \mathrm{MPa}$. Consequently, their method yielded an AARD\% of $4.5 \%$. The weakness of their model was its lack of predictive capability for ILs without any experimental data, as the model needed experimental data to evaluate $R^{*}$.

In a different approach, Krossing and Slattery [42] concluded that viscosity increased exponentially with increasing the molecular volume $\left(V_{m}\right)$. It was found that the relationship between viscosity and molecular volume was independent of the cation structure for a large range of common cations. However, it was highly anion dependent thus two coefficients should be calculated for each anion and they are valid for a limited range of temperature (i.e. $20-22^{\circ} \mathrm{C}$ ) [43]. Moreover functionalized cations are required their own pair of coefficients. As a result, 
cation and anion specific coefficients as well $V_{m}$ should be available for prediction of viscosity. These limitations hurt the applicability of this approach, especially for the prediction of viscosity of ionic liquids before synthesis which the coefficients are not available. $V_{m}$ is another property which should be measured by experiments or by application of Equation of State (EOS) theories [42-45].

To overcome the limitations of previous method, Eiden et al. [46] presented a novel approach and proposed a new temperature-dependent correlation without further input of any experimental data. For the viscosity, the inputs are only some basic physical observables like the Gibbs solvation energy which was calculated using Quantum Mechanics at the DFT-level (RI)BP86/TZVP/COSMO, the molecular radius, calculated from the molecular volume $V_{m}$ of the ion volumes, and the symmetry number $(\sigma)$, according to group theory. The model was tested with some success on 83 ILs (9 different cations and 11 anions) with a RMSE of 0.26 . Despite the apparent simplicity of the correlation, complicated Quantum Mechanics calculations have to be performed using special software like Gaussian [47] and Cosmotherm.

In another study, Bulut et al. [48] investigated the temperature dependence of the viscosity of mildly functionalized and non-functionalized $[\mathrm{Tf} 2 \mathrm{~N}]^{-}$ionic liquids. They used Arrhenius, Litovitz, and Vogel-Fulcher-Tammann (VFT) equations as well as the molecular volume $\left(V_{m}\right)$ to fit the experimental viscosity data. They found that VFT equation had the best fit, but it needed an empirical fitting parameter $T_{0}$. This parameter can be estimated if the glass transition temperature $\left(T_{g}\right)$ of the ionic liquid is known, otherwise the VFT equation is not applicable for prediction of the viscosity of ionic liquids with unknown value of $T_{g}$. 
Gardas and Coutinho [49] developed a group contribution (GC) model which could predict the viscosity of ionic liquids based on an Orrick-Erbar-type [50] equation. They developed the model by using 500 data points for 30 ionic liquids with 8 anion and 3 cation types. In terms of performance, the AARD\% of the model is $7.7 \%$. The model developed however requires the density of the ionic liquids as an input, which may be considered as a disadvantage of the approach [51]. This drawback was solved by Gardas and Coutinho [52] by developing a new model for 25 ILs based on the Vogel-Tammann-Fulcher (VTF) equation. Despite this improvement, the main disadvantage of the two models of Gardas and Coutino is the limited number of cations and anions used to develop the models which limits the applicability of the model for ionic liquids.

The first nonlinear Quantitative Structure-Property Relationship (QSPR) based model was developed by Yamomoto [53] for 62 ILs with a $\mathrm{R}^{2}$ of 0.9464 . The model shows fairly good results, but it is limited to 6 anions. Thereafter Yamomoto and co-workers [54, 55] developed new nonlinear GC and QSPR models for 300 data points. Their last model has a $\mathrm{R}^{2}$ of 0.931 and an average error of $5.04 \%$ on a logarithmic scale which translates into a "real" average error of 21.84\%. This model has the same weakness in terms of applicability for a limited number of cations and anions.

Bini et al. [56] presented two 4-parameter QSPR models for 30 ILs at two different temperatures (293 K and $353 \mathrm{~K}$ ). Their model failed to correlate/predict nitrile-functionalized cations and it is also limited to a relatively small number of ionic liquids.

Gharagheizi et al. [57] reported a 47-parameter GC model for 443 ILs with 1672 data points. The model has a $\mathrm{R}^{2}$ of 0.874 and an average error of $6.32 \%$ on a logarithmic scale; 
however, the "real" average error on a linear scale is nearly $31 \%$. The data used to develop the model contained 638 duplicated experimental values; thus only 1034 of the data points used were unique. Consequently, by removing the duplicated values, the average error in terms of $\log \eta$ and $\eta$ increases to $7.1 \%$ and $35.7 \%$ respectively. In addition, the database used contains 724 data points for fluorine-containing ionic liquids (F-ILs) which is less than the dataset used in this study (863 data points). The average error of this model only for F-ILs is $6.7 \%$ and $59.7 \%$ for logarithmic and linear scales. It is obvious that this model fails to predict the viscosity of F-ILs.

There have been studies by Valderrama et al. [58] and Billard et al. [59] on Neural Network modeling for viscosity, but these have been for limited numbers of ILs at a single temperature. The summary of the previous models are shown in Table 1.

Table 1: Summary of different models for predicting the $\ln (\eta)$ of ILs.

\begin{tabular}{|c|c|c|c|c|c|}
\hline Model & Model Type and parameters & $\mathrm{N}_{\text {ILs }}$ & $\mathrm{N}_{\text {data }}$ & AARD $\%$ & Comments \\
\hline Abbott [40] & Correlation & 11 & n.a. & 122 & 10 ILs contained fluorine atom. \\
\hline $\begin{array}{l}\text { Bandres } \\
\text { et al. }[41]\end{array}$ & Correlation & 8 & n.a. & 4.5 & 7 ILs contained fluorine atom. \\
\hline $\begin{array}{l}\text { Eiden et al. } \\
\text { [46] }\end{array}$ & $\begin{array}{l}\text { Correlation, } 3 \text { parameters } \\
\text { (Quantum Mechanics) }\end{array}$ & 155 & 810 & n.a. & $\begin{array}{l}122 \text { ILs contained fluorine atom. } \\
\text { RMSE is } 0.26 \text { for external } \\
\text { validation dataset ( } 83 \text { ILs with } 145 \\
\text { data points) }\end{array}$ \\
\hline $\begin{array}{l}\text { Gardas and } \\
\text { Coutinho [49] }\end{array}$ & GC, 13 parameters, $\rho$ & 30 & 500 & $7.78^{*}$ & $\begin{array}{l}\text { Only } 19 \text { ILs contained fluorine } \\
\text { atom. } \\
{ }^{*} \text { AARD } \% \text { is in linear scale. }\end{array}$ \\
\hline $\begin{array}{l}\text { Gardas and } \\
\text { Coutinho [52] }\end{array}$ & GC, 12 parameters & 25 & 482 & $7.50^{*}$ & $\begin{array}{l}\text { Only } 16 \text { ILs contained fluorine } \\
\text { atom. }\end{array}$ \\
\hline
\end{tabular}




\begin{tabular}{|c|c|c|c|c|c|}
\hline Model & Model Type and parameters & $\mathrm{N}_{\text {ILs }}$ & $\mathrm{N}_{\text {data }}$ & AARD \% & Comments \\
\hline & & & & & ${ }^{*} \mathrm{AARD} \%$ is in linear scale. \\
\hline $\begin{array}{l}\text { Tochigi and } \\
\text { Yamomoto [55] }\end{array}$ & QSPR, 24 parameters & 161 & 334 & 5.04 & $\begin{array}{l}149 \text { ILs contained fluorine atom. } \\
\text { Most of the ILs had just one data } \\
\text { point. }\end{array}$ \\
\hline Bini el al. [56] & QSPR, 4 parameters. & 33 & 66 & n.a. & $\begin{array}{l}\text { Authors proposed two models for } \\
\mathrm{T}=293 \mathrm{~K} \text { and } \mathrm{T}=353 \mathrm{~K} \text {. }\end{array}$ \\
\hline $\begin{array}{l}\text { Gharagheizi } \\
\text { et al. [57] }\end{array}$ & GC, 47 parameters & 443 & 1672 & 6.32 & $\begin{array}{l}638 \text { duplicated data points were } \\
\text { used. } \\
\text { By removing the duplicates, the } \\
\text { AD\% was risen to } 7.1 \% \text {. } \\
724 \text { data points were for F-ILs }\end{array}$ \\
\hline $\begin{array}{l}\text { Valderrama } \\
\text { et al. }[58]\end{array}$ & ANN & 58 & 327 & n.a. & \\
\hline $\begin{array}{l}\text { Billard } \\
\text { et al. [59] }\end{array}$ & ANN & 99 & 99 & 10 & The data were only at $298 \mathrm{~K}$. \\
\hline GC Model (1) & GC, 35 parameters & 85 & 863 & 3.23 & $\begin{array}{l}\text { The reliable data sources were } \\
\text { used. }\end{array}$ \\
\hline GC Model (2) & GC, 36 parameters & 332 & 1160 & 4.85 & $\begin{array}{l}\text { The entire database including } \\
\text { unreliable data sources was used. }\end{array}$ \\
\hline
\end{tabular}

This study presents a general predictive GC model to correlate and estimate the viscosity with temperature dependency of fluorine-containing ionic liquids. The performance and accuracy of the GC model was evaluated by undertaking statistical and graphical error analyses of the results.

\section{Methodology}




\subsection{Databank}

Viscosity of ionic liquids is one of the hardest properties to model. Because the presence of small amount of contaminants in ionic liquids changes the viscosity drastically. Seddon et al.[60] showed that contamination with water decreases the viscosity, while the presence of chloride ions increases the viscosity. As a result, it was required to select the experimental data of viscosity very carefully and use the reliable sources.

The NIST Standard Reference Database \#103b [61] was used to extract temperature dependent data of viscosity for 85 fluorine-containing ILs. There were in total 863 data points. The selected ILs were composed of 58 unique cations and 9 unique anions. The dataset has an extensive range of temperatures from 258.15 to $388.51 \mathrm{~K}$ and a wide range of viscosity values from 4.1 to $3067.3 \mathrm{cp}$. Figure 1 shows the number of ionic liquids in the different families including ammonium, imidazolium, phosphonium, pyridinium, pyrrolidinium, and quinolinium. The abbreviations and chemical structures of the cations and anions used in this study are available in Tables S1 and S2 in supplementary materials. 


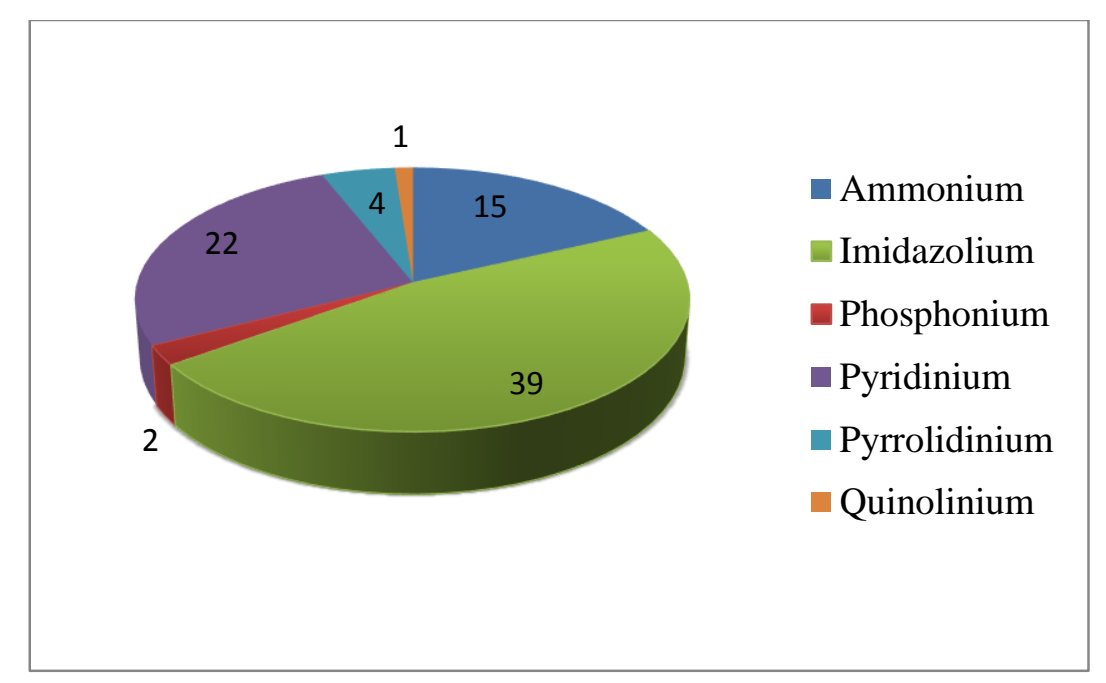

Fig. 1: The number of ionic liquids in different families used to model the viscosity (refined dataset).

Zhang et al. [62] gathered lots of data from different sources such as patents and papers and published them as a text book entitled "Ionic Liquids:: Physicochemical Properties", which has been used extensively by Gharagheizi et al. [57]. The screening procedure was performed on the dataset reported by by Gharagheizi et al. and after removing lots of duplicated values, 297 new data points for 247 different ionic liquids were remained. It was observed that most of these new ionic liquids just had one data point at a constant temperature without any reported uncertainties. Some of these ionic liquids are used by Krossing [42, 63]. In addition, some data points seemed to be erroneous. For example, the viscosity of "1-butyl-3-[3-(2hydroxybenzylamino)propyl]-3H-imidazolium hexafluorophosphate" was reported originally by Quadi et al. [64] as $257,000 \mathrm{cP}$ which seems as outlier compared with viscosity of other ionic liquids. Unfortunately, Quadi et al. didn't report the temperature of the measurement; so 
Gharagheizi et al. assumed that it was measured at $298.15 \mathrm{~K}$. Most of the data of these new ionic liquids suffered from unreported value of temperature.

The initial steps of modeling revealed that these new data were not reliable as they had large deviations from the predicted values (mostly more than 70\%). As a result, it was decided to ignore these data to avoid negative effects of accuracy of the model developed. However, another model was developed using the entire dataset (1160 data points for 332 ionic liquids shown in Figure 2) and the output of this model was illustrated in a separate figure. The datasets used for two developed models as well as the models parameters are reported in supplementary materials.

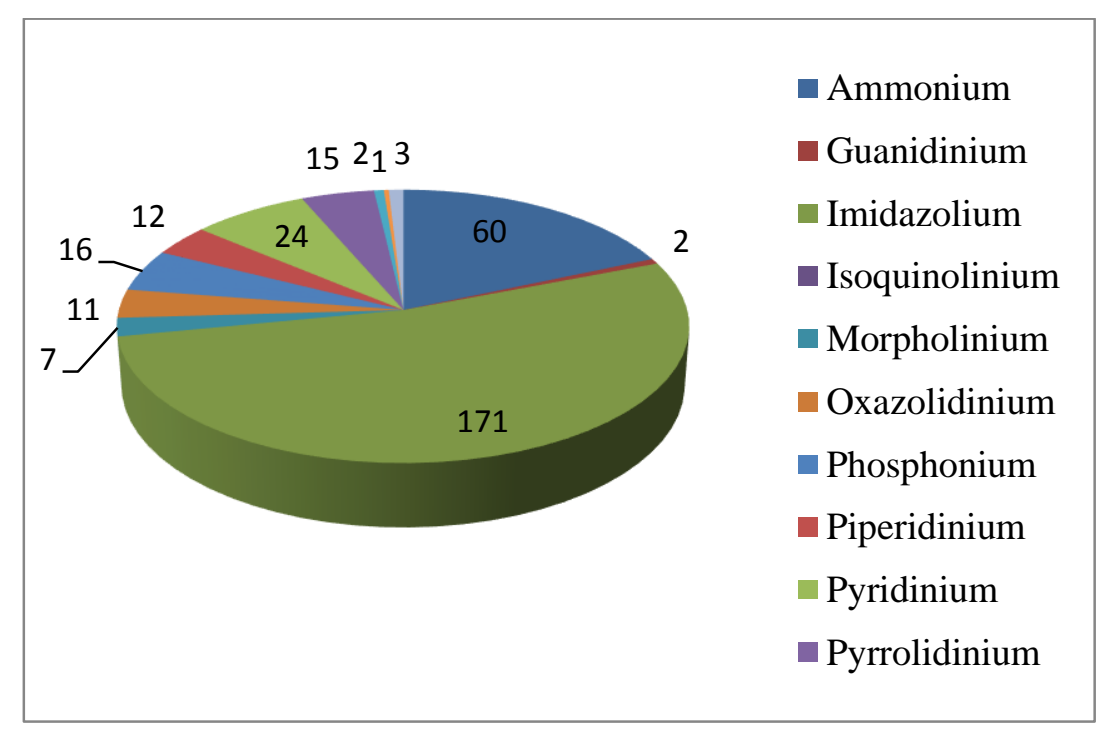

Fig. 2: The number of ionic liquids in different families used to model the viscosity (unreliable dataset).

The data used in the model development was screened as follows: 
1) Where there were several reported values of viscosity for a single temperature, the value with the lowest uncertainty was incorporated into dataset utilized.

2) If the reported values had the same uncertainties, the latest published values were utilized.

The complete data set of viscosity values utilized, including the original reference sources of the experimental data are presented as supplementary materials.

\subsection{Data Preparation}

During the development of GC models, the database is divided into two subsets: a "training" and "test" datasets. The training set is utilized to develop the GC model and the test set is implemented to evaluate the reliability and prediction capability of the model. In order to distribute similar compounds into both subsets and overcome the problem of unsuitable allocation of subsets, cluster analysis is undertaken to maintain as close as possible a similarity between training and test subsets.

One of the most important methods of cluster analysis is $K$-means clustering which divides $n$ observations into $k$ clusters in which each observation is counted within the cluster with the nearest mean $[65,66]$. The quota for each subset from the main database is another point for considering in partition of all data points. In this study, approximately $80 \%$ (667 data points) and $20 \%$ (196 points) of the main dataset were allocated to the training and test sets, respectively. 


\section{Developing the Group Contribution Model}

In group contribution (GC) models, it is assumed that the property of a compound is a function of structurally-dependent parameters which is calculated by summing the frequency of each functional group occurring in the molecule. As a result, the GC method gives the benefit of fast-estimations without the need for substantial computational resources [67]. To determine the most effective substructures for the viscosity of fluorine-containing ionic liquids, the chemical structures of all the ILs used was thoroughly examined. The substructures and their number of events/occurrences in chemical structures of cations and anions plus the absolute temperature were applied as the input parameters of the GC model.

Generally, it is assumed that the viscosity can be modeled using the more complex form Arrhenius equation, $\eta=\exp (f(T))$. As a result of greater reliability being required for smaller values of viscosity, taking the logarithm will increase the accuracy for small values of viscosity [55]. In this study, it was assumed that $\ln (\eta)$ had a multi-linear relationship with functional groups. This assumption is common in GC modeling and generally works. In case of failure, the nonlinear combinations of functional groups are used. Moreover, a nonlinear relationship between $\ln (\eta)$ and absolute temperature was used. The temperature dependency was assumed as

$f\left(\frac{1}{T}, \frac{1}{T^{2}}\right)[46]$. Consequently, the "training" set was used to select the effective substructures and fine tuning the temperature nonlinear function in a polynomial form.

It is notable that ILs are glass former and typically one has to use the VFT approach (Eq. 1) to model the viscosity in a wider range, i.e. close to melting point [68]. 


$$
\ln (\eta)=\ln \left(\eta_{0}\right)+\frac{A}{T-T_{0}}
$$

As the Vogel temperature $T_{0}$ was an IL specific quantity and the $\eta_{0}$ was not available for most of the ionic liquids, unfortunately the VFT approach was not applicable. As a result, the Arrhenius equation was used in this study.

\section{Results and Discussion}

As mentioned above, the refined dataset of viscosity data with total 863 data points were used to develop the model. The modeling results revealed that the best model with the lowest possible number of variables was a 35-parameter model with a total $\mathrm{R}^{2}=0.977$, as is shown in Eq. (2).

$$
\begin{aligned}
& \ln (\eta)=A+B\left(\frac{1000}{T}\right)+C\left(\frac{1000}{T}\right)^{2} \\
& A=\sum_{i=1}^{k} n_{i} a_{i}, B=\sum_{i=1}^{k} n_{i} b_{i}, C=\sum_{i=1}^{k} n_{i} c_{i}
\end{aligned}
$$

where $T$ is the absolute temperature, $n_{i}$ is the number of groups of type $i, k$ is the total number of different types of groups, and the parameters $a_{\mathrm{i}}, b_{i}$, and $c_{i}$ are for different substructures. The model parameters are available in Table 2. 
Table 2: Parameters of the GC model in Eq. (2)

\begin{tabular}{|c|c|c|c|c|c|}
\hline No. & Chemical structure & Descriptions & $a_{i}$ & $\boldsymbol{b}_{i}$ & $c_{i}$ \\
\hline & Intercept & & 5.05776 & & \\
\hline 1 & $\mathrm{nR} 06_{C a t}$ & number of 6-membered rings & 0.15706 & & \\
\hline 2 & $\mathrm{nCp}_{\text {Cat }}$ & number of terminal primary $\mathrm{C}(\mathrm{sp} 3)$ & -0.34962 & & \\
\hline & & $\mathrm{Y}=$ any terminal atom or heteroaromatic & & & \\
\hline 3 & $\mathrm{nCrs}_{C a t}$ & $\begin{array}{l}\text { number of total secondary } \mathrm{C}(\mathrm{sp} 3) \\
\mathrm{Y}=\mathrm{H} \text { or any heteroatom }\end{array}$ & 0.26051 & & \\
\hline 4 & nCconj $_{\text {Cat }}$ & number of non-aromatic conjugated $\mathrm{C}(\mathrm{sp} 2)$ & -1.81670 & & \\
\hline 5 & $(\mathrm{R}-\mathrm{C}(=\mathrm{X})-\mathrm{X} / \mathrm{R}-\mathrm{C} \equiv \mathrm{X} / \mathrm{X}=\mathrm{C}=\mathrm{X})_{C a t}$ & $\mathrm{X}$ represents any heteroatom $(\mathrm{O}, \mathrm{N}, \mathrm{S}, \mathrm{P}, \mathrm{Se}$, halogens) & -3.58447 & 0.69161 & \\
\hline 6 & {$\left[\mathrm{C}-(\mathrm{A})_{3}-\mathrm{C}\right]_{\mathrm{Cat}}$} & A represents any atom & -0.08890 & & \\
\hline 7 & {$\left[\mathrm{C}-(\mathrm{A})_{3}-\mathrm{N}\right]_{C a t}$} & & -0.21752 & & \\
\hline 8 & {$\left[\mathrm{C}-(\mathrm{A})_{5}-\mathrm{C}\right]_{\mathrm{Cat}}$} & & 0.02554 & & \\
\hline 9 & {$\left[\mathrm{C}-(\mathrm{A})_{5}-\mathrm{N}\right]_{C a t}$} & & -0.15649 & & \\
\hline 10 & {$\left[\mathrm{C}-(\mathrm{A})_{8}-\mathrm{P}\right]_{C a t}$} & & -5.34117 & & \\
\hline 11 & $(\mathrm{R}-\mathrm{C}(=\mathrm{X})-\mathrm{X} / \mathrm{R}-\mathrm{C} \equiv \mathrm{X} / \mathrm{X}=\mathrm{C}=\mathrm{X})_{A n}$ & & -0.39713 & & \\
\hline 12 & $\mathrm{nR}=\mathrm{Ct}_{\text {Cat }}$ & number of aliphatic tertiary $\mathrm{C}(\mathrm{sp} 2)$ & & 2.11721 & \\
\hline 13 & $\mathrm{nN}^{+}$Cat & number of positive charged $\mathrm{N}$ & & -4.57101 & \\
\hline 14 & $(\mathrm{CH} 3 \mathrm{R} / \mathrm{CH} 4)_{\mathrm{Cat}}$ & & & 0.32222 & \\
\hline 15 & $\mathrm{CH} 3 \mathrm{X}_{\text {Cat }}$ & & & 0.16892 & \\
\hline 16 & {$\left[\mathrm{C}-(\mathrm{A})_{4}-\mathrm{N}\right]_{C a t}$} & & & 0.04905 & \\
\hline 17 & {$\left[\mathrm{C}-(\mathrm{A})_{4}-\mathrm{O}\right]_{\mathrm{Cat}}$} & & & -0.14875 & \\
\hline
\end{tabular}




\begin{tabular}{|c|c|c|c|c|c|}
\hline No. & Chemical structure & Descriptions & $a_{i}$ & $\boldsymbol{b}_{i}$ & $c_{i}$ \\
\hline 18 & {$\left[\mathrm{C}-(\mathrm{A})_{5}-\mathrm{O}\right]_{C a t}$} & & & 0.14203 & \\
\hline 19 & $\mathrm{nP}_{A n}$ & number of Phosphorous atoms & & -0.42847 & \\
\hline 20 & {$\left[\mathrm{C}-(\mathrm{A})_{2}-\mathrm{O}\right]_{A n}$} & & & 0.03122 & \\
\hline 21 & $\mathrm{nO}_{\text {Cat }}$ & number of Oxygen atoms & & & 0.17796 \\
\hline 22 & nArNR2 ${ }_{\text {Cat }}$ & $\begin{array}{l}\text { number of tertiary amines (aromatic) } \\
\mathrm{Y}=\text { Aromatic or Aliphatic }(\operatorname{not} \mathrm{C}=\mathrm{O})\end{array}$ & & & -0.94346 \\
\hline 23 & $\mathrm{CH} 2 \mathrm{R} 22_{C a t}$ & & & & 0.02528 \\
\hline 24 & $\mathrm{R}-\mathrm{CH}-\mathrm{-R}$ Cat & & & & 0.05543 \\
\hline 25 & $(\mathrm{R}-\mathrm{-N}--\mathrm{R} / \mathrm{R}-\mathrm{-N}-\mathrm{X})_{C a t}$ & & & & 0.20778 \\
\hline 26 & {$[\mathrm{C}-\mathrm{N}]_{\text {Cat }}$} & & & & 0.28852 \\
\hline 27 & {$[\mathrm{~N}-\mathrm{A}-\mathrm{N}]_{\text {Cat }}$} & & & & -0.75415 \\
\hline 28 & {$\left[\mathrm{C}-(\mathrm{A})_{2}-\mathrm{N}\right]_{C a t}$} & & & & 0.01301 \\
\hline 29 & {$\left[\mathrm{~N}-(\mathrm{A})_{2}-\mathrm{O}\right]_{C a t}$} & & & & 0.57373 \\
\hline 30 & {$\left[\mathrm{C}-(\mathrm{A})_{3}-\mathrm{O}\right]_{\mathrm{Cat}}$} & & & & -0.21222 \\
\hline 31 & {$\left[\mathrm{C}-(\mathrm{A})_{4}-\mathrm{C}\right]_{C a t}$} & & & & 0.00218 \\
\hline 32 & {$\left[\mathrm{C}-(\mathrm{A})_{8}-\mathrm{C}\right]_{\mathrm{Cat}}$} & & & & -0.00526 \\
\hline 33 & {$\left[\mathrm{C}-(\mathrm{A})_{8}-\mathrm{N}\right]_{\text {Cat }}$} & & & & 0.02693 \\
\hline 34 & {$[\mathrm{P}-\mathrm{F}]_{A n}$} & & & & 0.03452 \\
\hline 35 & {$\left[\mathrm{~S}-(\mathrm{A})_{3}-\mathrm{F}\right]_{A n}$} & & & & -0.01262 \\
\hline
\end{tabular}

A represents any atom type.

$\mathrm{R}$ represents any group linked through carbon.

$\mathrm{X}$ represents any heteroatom $(\mathrm{O}, \mathrm{N}, \mathrm{S}, \mathrm{P}, \mathrm{Se}$, halogens).

-- represents an aromatic bond as in benzene or delocalized bonds such as the N-O bond in a nitro group.

To assess the performance and accuracy of the GC model developed for prediction of the viscosity of fluorine-containing ILs, statistical error analyses were undertaken, the results of which are summarized in Table 3. The results show that the total average absolute relative deviation (AARD\%) of the model is $3.23 \%$ (2.91\% for the training set and $4.31 \%$ for the test 
set). In addition, $\mathrm{R}^{2}$ is 0.977 for all data points, 0.981 for the training set and 0.966 for the test set.

Table 3: The statistical error parameters for $\ln (\eta)$ in Eq. (2)

\begin{tabular}{|c|c|}
\hline \multicolumn{2}{|l|}{ Statistical Parameter } \\
\hline \multicolumn{2}{|l|}{ training set } \\
\hline $\mathrm{R}^{2 \mathrm{a}}$ & 0.981 \\
\hline Average absolute relative deviation ${ }^{\mathrm{b}}$ & 2.91 \\
\hline Standard deviation error ${ }^{\mathrm{c}}$ & 0.17 \\
\hline Root mean square error ${ }^{\mathrm{d}}$ & 0.18 \\
\hline No. of data points & 667 \\
\hline \multicolumn{2}{|l|}{ test set } \\
\hline $\mathrm{R}^{2}$ & 0.966 \\
\hline Average absolute relative deviation & 4.31 \\
\hline Standard deviation error & 0.25 \\
\hline Root mean square error & 0.25 \\
\hline No. of data points & 196 \\
\hline \multicolumn{2}{|l|}{ total } \\
\hline $\mathrm{R}^{2}$ & 0.977 \\
\hline Average absolute relative deviation & 3.23 \\
\hline Standard deviation error & 0.19 \\
\hline Root mean square error & 0.19 \\
\hline No. of data points & 863 \\
\hline \multicolumn{2}{|l|}{${ }^{\mathrm{a}} R^{2}=1-\frac{\sum_{i=1}^{N}\left[y(i)_{c a l c}-y(i)_{\text {exp }}\right]^{2}}{\sum_{i=1}^{N}\left[y(i)_{c a l c}-\bar{y}_{\text {exp }}\right]^{2}}$} \\
\hline \multicolumn{2}{|l|}{${ }^{\mathrm{b}} A A R D \%=\frac{100}{N} \sum_{i=1}^{N}\left|\frac{y(i)_{\text {calc }}-y(i)_{\exp }}{y(i)_{\exp }}\right|$} \\
\hline${ }^{\mathrm{c}} S D E C=\sqrt{\frac{1}{N} \sum_{i=1}^{N}[e(i)-\bar{e}]^{2}},(e=$ & $\left.y_{\text {calc }}-y_{\text {exp }}\right)$ \\
\hline${ }^{\mathrm{d}} R M S E=\sqrt{\frac{1}{N} \sum_{i=1}^{N}\left[y(i)_{\text {calc }}-y(i)\right.}$ & \\
\hline
\end{tabular}


The calculated/predicted viscosities of F-ILs used in this study and their families are available in Table S1 in supplementary materials and Table 4, respectively. In addition, the cross-plot of experimental data versus calculated/predicted data and the relative deviation of $\ln \left(\eta_{\text {Pred }}\right)$ from experimental data are presented in Fig. 3 and Fig. 4, respectively. The correlated viscosities of F-ILs and their absolute relative deviation from the reported values are available as supplementary materials.

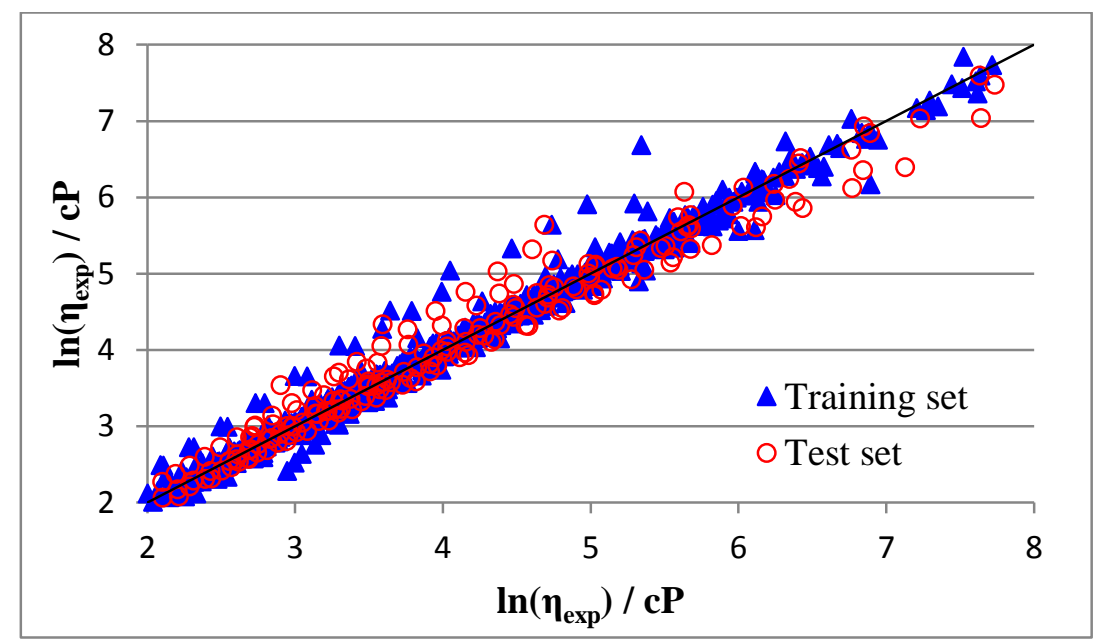

Fig. 3: Predicted versus experimental values of $\ln (\eta)$ (refined database) (— diagonal line). 


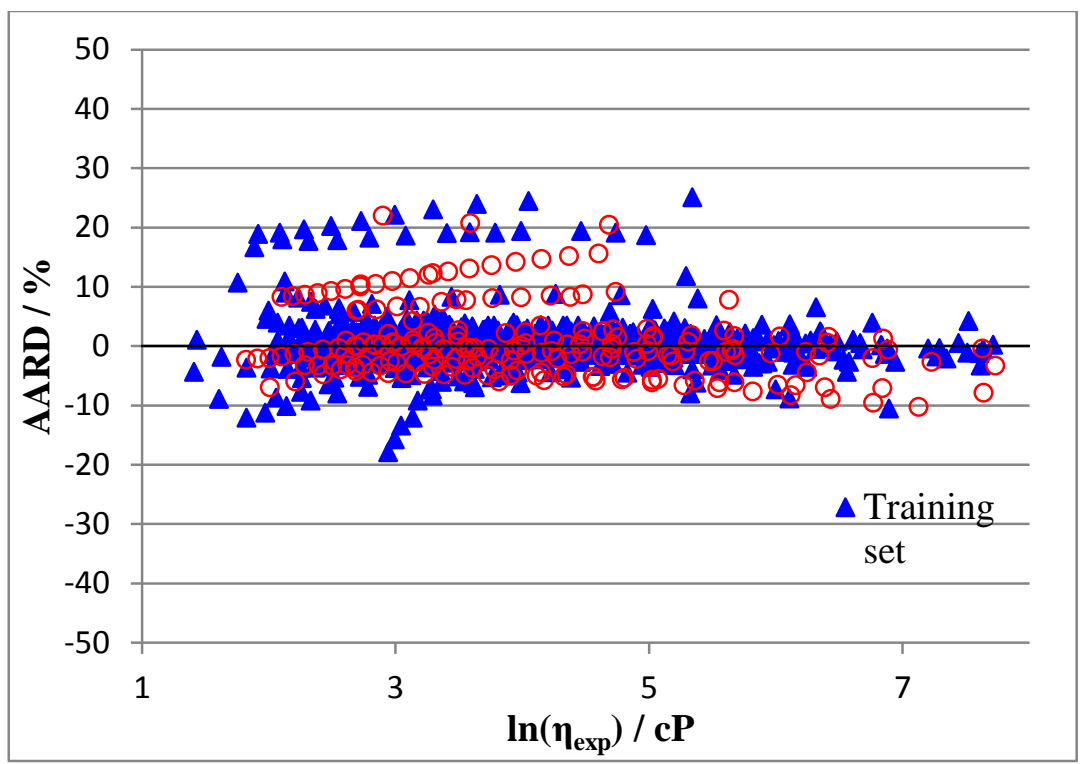

Fig. 4: Relative deviation of predicted $\ln (\eta)$ from experimental data (refined database).

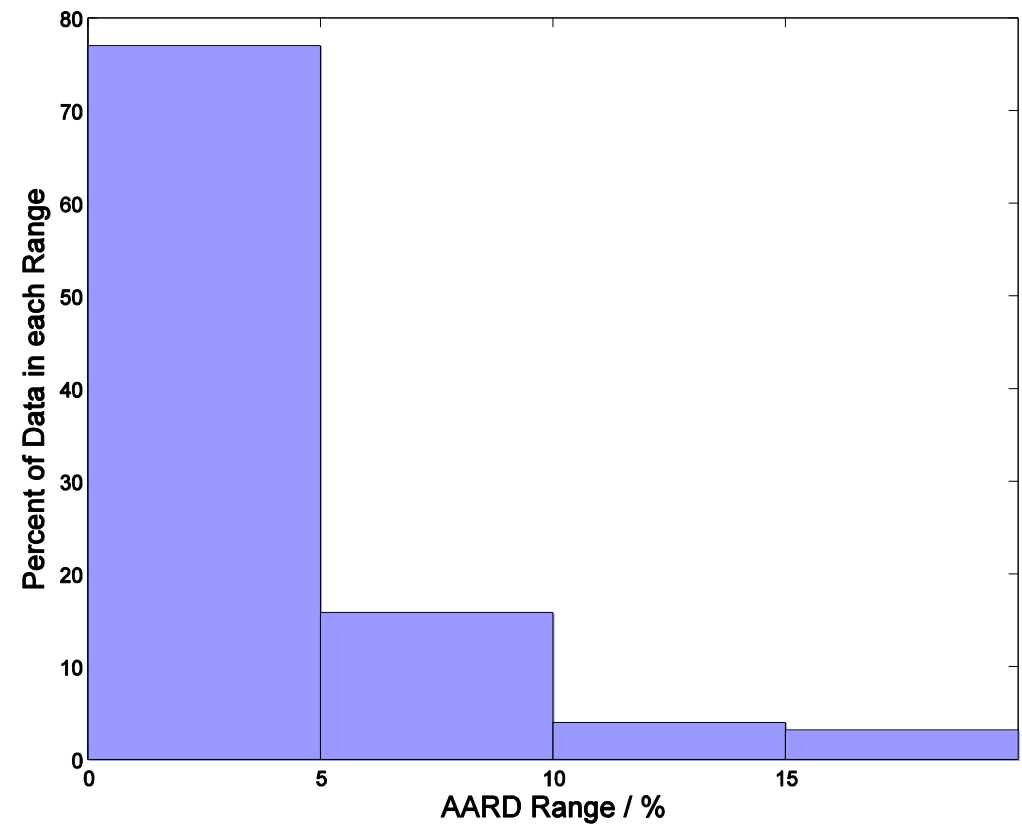

Fig. 5: Percentage of correlated/predicted values of $\ln (\eta)$ in different relative deviation ranges. 
According to Fig. 3, a tight cluster of points near the diagonal for the training and testing datasets illustrates the robustness of the proposed GC model for the prediction of the viscosity of F-ILs. Fig. 5 demonstrates the percentage of correlated/predicted values of $\ln (\eta)$ in different relative deviation ranges. It shows that $77 \%$ of the calculated values are within an AARD range of $0-5 \%, 16 \%$ within range of $5-10 \%$, approximately $4 \%$ within the range of $10-15 \%$ and only $3 \%$ within the range of $15-25 \%$. According to Table S1, most of data points with high deviations are for temperatures over $330 \mathrm{~K}$ or for very low viscosity values, for which a small deviation in predicted viscosity produces large AARD\% values.

Another possible reason for the observed deviations for the model prediction/correlation is due to unreliability in viscosity values of ILs which are not as pure as claimed. According to Seddon et al.[60] study, the presence of contaminants in ionic liquids changes the viscosity drastically; for example contamination with water decreases the viscosity, while the presence of chloride ions increases the viscosity. That is one of the main reasons for the existence of multiple reported values of viscosity at a single temperature in the literature. In addition, 1-ethyl-3methylimidazolium ILs have higher water-solubility than 1-butyl-3-methylimidazolium ILs, which makes them much more difficult to be purified [69].

The other reason for such deviations may be because of missing certain functional groups or their combinations in the model. For example, the average deviation for 1-ethyl-3methylimidazolium ILs is $10.69 \%$ while it is $2.22 \%$ for 1-butyl-3-methylimidazolium and $3.9 \%$ for 1-hexyl-3-methylimidazolium ILs. Along with the purification problem, it seems that the model needs some additional functional groups of anions just for 1-ethyl-3-methylimidazolium ILs to have a better prediction. By adding a correction term to Eq. 2 and including 6 more 
functional groups, the deviation of these ionic liquids decreases to $1.4 \%$. As shown in Eq. 3, the corrected model is more complicated and has higher number of parameters which is not desirable in this study; however the correction term is available in supplementary materials.

$$
\begin{aligned}
& \ln (\eta)=A+B\left(\frac{1000}{T}\right)+C\left(\frac{1000}{T}\right)^{2}+f(\text { EMIM }) \\
& f(E M I M)=X+Y\left(\frac{1000}{T}\right)+Z\left(\frac{1000}{T}\right)^{2} \\
& X=\sum_{i=1}^{k} n_{i} x_{i}, Y=\sum_{i=1}^{k} n_{i} y_{i}, Z=\sum_{i=1}^{k} n_{i} z_{i}
\end{aligned}
$$

Table 4 shows the AARD\% of each family of ionic liquids (without applying the correction term). The results indicate that the model can correlate and predict each family with a similar averaged accuracy and demonstrates the comprehensiveness of the model. The maximum deviation is observed in imidazolium (4.51\%) ILs and the minimum in ammonium ILs (1.60\%). It should be noted that the quinolinium family has the absolute minimum deviation (0.29\%); but as there is just one ionic liquid in that family, it cannot be considered as a well-predicted class of ILs.

Table 4: The AARD\% of Eq.2 for different families of ionic liquids.

\begin{tabular}{ccccccc}
\hline No. & Family & T $(\mathbf{K})$ range & $\ln (\boldsymbol{\eta})(\mathbf{c P})$ & AARD\% & N Compounds & N Data Points \\
\hline 1 & Ammonium & $283-388.51$ & $1.887-7.616$ & 1.60 & 15 & 87 \\
2 & Imidazolium & $258.15-388.19$ & $1.411-7.716$ & 4.51 & 39 & 393 \\
3 & Phosphonium & $268.15-373.15$ & $2.866-8.027$ & 3.86 & 2 & 40 \\
4 & Pyridinium & $278.15-373.15$ & $1.823-7.512$ & 1.72 & 22 & 249 \\
5 & Pyrrolidinium & $258.15-373.15$ & $1.983-7.733$ & 3.29 & 4 & 88 \\
6 & Quinolinium & $323.15-348.15$ & $3.533-4.606$ & 0.29 & 1 &
\end{tabular}


To have a better judgment about the model proposed, Fig. 6 shows the "real" linear scale values of viscosity; however it is common to report just the accuracy of the model in logarithmic scale. By reversing the Arrhenius equation and applying the $\exp$ on the data, the "real" AARD\% of the model became $13.31 \%$ which is very low compared with the previous models, as shown in Table 1.

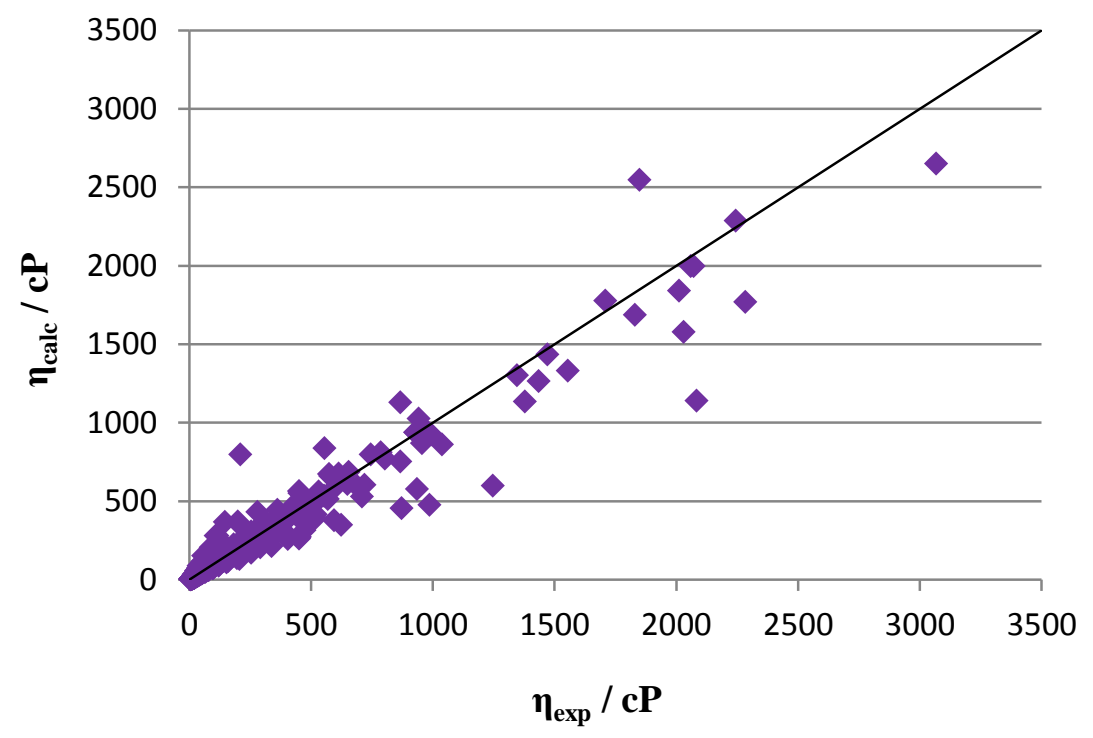

Fig. 6: Predicted versus experimental values of $\eta$ in linear scale (refined database) ( - diagonal line).

As discussed before, the viscosity data of 247 ILs with 297 data points were excluded from the development of the model proposed, because there were not any reported uncertainty values for those data points. To have a comprehensive but less accurate model, all available data points (1160 data points) were used to develop a new model. This new model had 36 parameters with an AARD\% of $4.85 \%$ in logarithmic scale and $21.89 \%$ in linear scale. Fig. 7 and Fig. 8 illustrate the result of model developed in logarithmic and linear scale. 


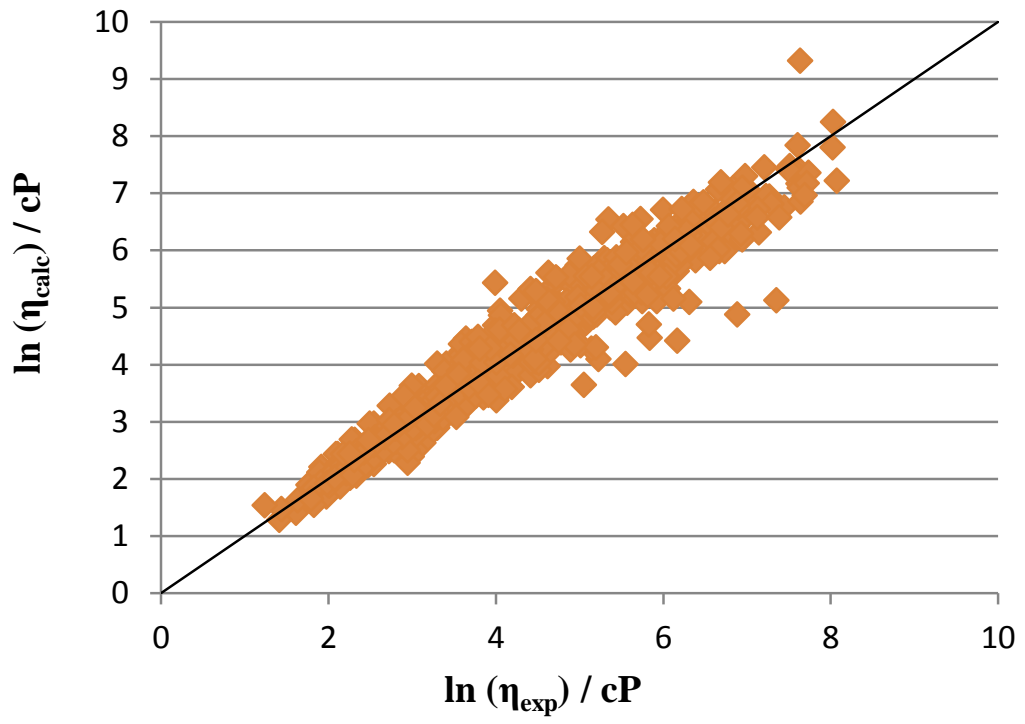

Fig. 7: Predicted versus experimental values of $\ln (\eta)$ (entire database) ( - diagonal line).

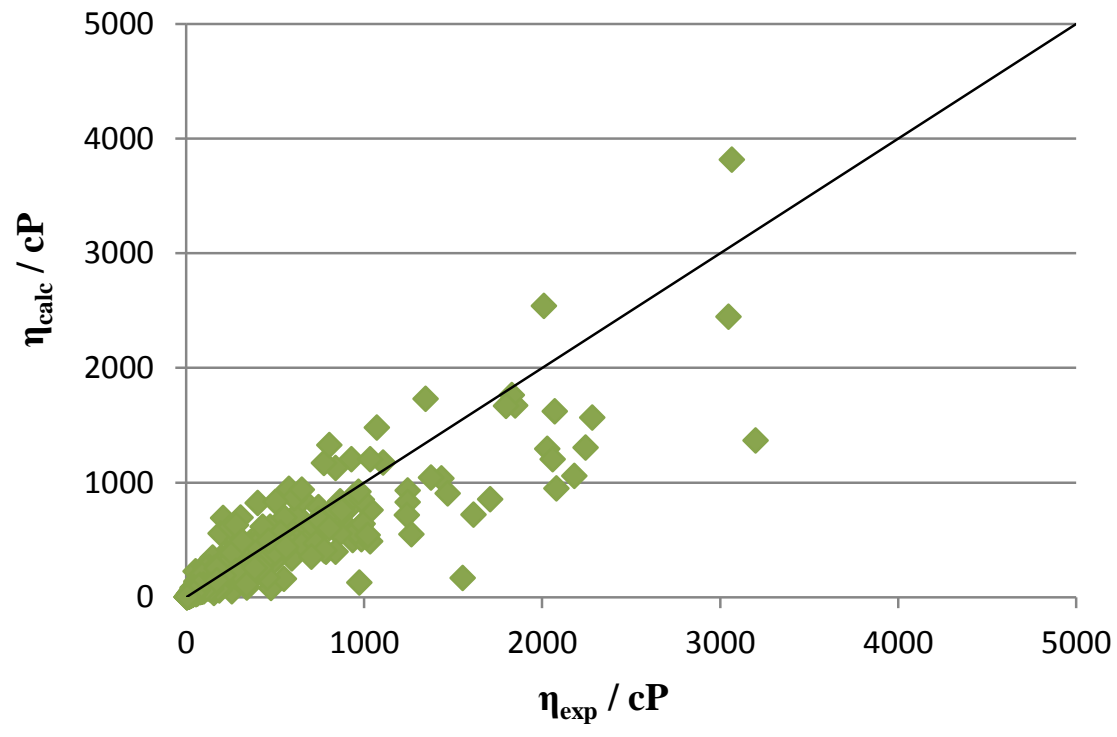

Fig. 8: Predicted versus experimental values of $\eta$ in linear scale (entire database) (- diagonal line). 
In comparison with the previous published models, these two models presented in this study have more accuracy and applicability for various ionic liquids. The first model which was developed based on less but refined data points, had an AARD $\%$ of $3.23 \%$ and $13.31 \%$ for $\ln (\eta)$ and $\eta$, respectively. Similarly, the second model, which was developed using some unreliable data points, had an AARD\% of $4.85 \%$ and $21.89 \%$ for $\ln (\eta)$ and $\eta$, respectively. According to the results, both can predict the viscosity of F-ILs more accurately compared with previous models.

All previous models were developed for few types of ionic liquids, except the models proposed by Eiden et al. [46] and Gharagheizi et al. [57]. Unfortunately, Eiden et al. did not publish the experimental and predicted values of viscosity, so a detailed comparison is not possible. Gharagheizi et al. used a dataset consisted of 1034 unique data points of which 724 were for F-ILs. By using only the data of F-ILs, that model showed an AARD\% of $6.7 \%$ and $59.7 \%$ for $\ln (\eta)$ and $\eta$ which the latter is a very large deviation and calls the applicability of this model for F-ILs into question. As a result, that model has lower accuracy compared with models presented in this study.

Information for the entire dataset, as well as the values of the functional groups of the ILs for both developed models are available in the supplementary materials.

\section{Conclusions}

For the viscosity of fluorine-containing ionic liquids, the available experimental data were used to create two different databases. The first one was screened carefully and unreliable data points were removed; so the refined database contained the experimental data points for 85 
F-ILs and it was used to develop a GC model. On the other hand, the second database included the unreliable data points for additional 247 different F-ILs and it was used to develop another GC model in order to have a comprehensive model for a wider range of ILs. Both models had the AARD $\%$ of below $5 \%$ for $\ln (\eta)$ which was less than the best model published in the literature. Consequently, from the results obtained in this study it can be concluded that the group contribution model developed can be used to select or design appropriate ionic liquids for a specific viscosity value range within the range of temperatures for which the model was developed.

\section{Acknowledgements}

The authors would like to thank Dr. Michael Frenkel of the National Institute of Standards and Technology for providing the NIST Standard Reference Database. This work is based upon research supported by the South African Research Chairs Initiative of the Department of Science and Technology and National Research Foundation. 


\section{References}

[1] B. Phillips, G. John, J. Zabinski, Surface chemistry of fluorine containing ionic liquids on steel substrates at elevated temperature using Mössbauer spectroscopy, Tribol. Lett. 26 (2007) 85-91.

[2] H. Xue, R. Verma, J.n.M. Shreeve, Review of ionic liquids with fluorine-containing anions, J. Fluorine Chem. 127 (2006) $159-$ 176.

[3] H. Xue, J.n.M. Shreeve, lonic Liquids with Fluorine-Containing Cations, Eur. J. Inorg. Chem. 2005 (2005) 2573-2580.

[4] H.N. Song, B.-C. Lee, J.S. Lim, Measurement of CO2 solubility in ionic liquids:[BMP][TfO] and [P14, 6, 6, 6][Tf2N] by measuring bubble-point pressure, J. Chem. Eng. Data 55 (2009) 891-896.

[5] M. Moosavi, A. Daneshvar, Investigation of the rheological properties of two imidazolium-based ionic liquids, J. Mol. Liq. 190 (2014) 59-67.

[6] L. Guo, X. Pan, C. Zhang, M. Wang, M. Cai, X. Fang, S. Dai, Novel hydrophobic cyclic sulfonium-based ionic liquids as potential electrolyte, J. Mol. Liq. 158 (2011) 75-79.

[7] M.M. Papari, S. Amighi, M. Kiani, D. Mohammad-Aghaie, B. Haghighi, Modification of a statistical mechanically-based equation of state: Application to ionic liquids, J. Mol. Liq. 175 (2012) 61-66.

[8] W. Wang, H. Yang, H. Cui, D. Zhang, Y. Liu, J. Chen, Application of Bifunctional lonic Liquid Extractants [A336][CA-12] and [A336][CA-100] to the Lanthanum Extraction and Separation from Rare Earths in the Chloride Medium, Ind. Eng. Chem. Res. 50 (2011) 7534-7541.

[9] A.E. Visser, W.M. Reichert, R.P. Swatloski, H.D. Willauer, J.G. Huddleston, R.D. Rogers, Characterization of Hydrophilic and Hydrophobic Ionic Liquids: Alternatives to Volatile Organic Compounds for Liquid-Liquid Separations, in: R.D. Rogers, K.R. Seddon (Eds.) Ionic Liquids, American Chemical Society, 2002, pp. 289-308.

[10] J. Gui, Y. Deng, Z. Hu, Z. Sun, A Novel Task-Specific lonic Liquid for Beckmann Rearrangement: A Simple and Effective Way for Product Separation, Tetrahedron Lett. 45 (2004) 2681-2683.

[11] M. Uerdingen, Ionic Liquids as Lubricants, in: P.T. Anastas (Ed.) Handbook of Green Chemistry, Wiley-VCH Verlag GmbH \& Co. KGaA, 2010, pp. 203-219.

[12] V. Khare, M.-Q. Pham, N. Kumari, H.-S. Yoon, C.-S. Kim, J.-I.L. Park, S.-H. Ahn, Graphene-lonic Liquid Based Hybrid Nanomaterials as Novel Lubricant for Low Friction and Wear, ACS Appl. Mater. Interfaces 5 (2013) 4063-4075.

[13] B.A. Kheireddin, W. Lu, I.C. Chen, M. Akbulut, Inorganic nanoparticle-based ionic liquid lubricants, Wear 303 (2013) $185-$ 190.

[14] A. Somers, P. Howlett, D. MacFarlane, M. Forsyth, A Review of lonic Liquid Lubricants, Lubricants 1 (2013) 3-21.

[15] P. Wasserscheid, M. Haumann, Catalyst Recycling Using Ionic Liquids, in: D. Cole-Hamilton, R. Tooze (Eds.) Catalyst Separation, Recovery and Recycling, Springer Netherlands, 2006, pp. 183-213.

[16] L. Fischer, T. Falta, G. Koellensperger, A. Stojanovic, D. Kogelnig, M. Galanski, R. Krachler, B.K. Keppler, S. Hann, Ionic liquids for extraction of metals and metal containing compounds from communal and industrial waste water, Water Res. 45 (2011) 4601-4614.

[17] X. Zeng, J. Li, H. Xie, L. Liu, A novel dismantling process of waste printed circuit boards using water-soluble ionic liquid, Chemosphere 93 (2013) 1288-1294.

[18] M.T. Hamed Mosavian, Z. Es'haghi, N. Razavi, S. Banihashemi, Pre-concentration and determination of amitriptyline residues in waste water by ionic liquid based immersed droplet microextraction and HPLC, J. Pharm. Anal. 2 (2012) 361-365.

[19] J.-C. Xiao, B. Twamley, J.n.M. Shreeve, An Ionic Liquid-Coordinated Palladium Complex: A Highly Efficient and Recyclable Catalyst for the Heck Reaction, Org. Lett. 6 (2004) 3845-3847.

[20] X. Chen, Y. Peng, Chloroferrate(III) Ionic Liquid: Efficient and Recyclable Catalyst for Solvent-free Synthesis of 3,4Dihydropyrimidin-2(1H)-ones, Catal. Lett. 122 (2008) 310-313.

[21] T.K. Carlisle, E.F. Wiesenauer, G.D. Nicodemus, D.L. Gin, R.D. Noble, Ideal CO2/Light Gas Separation Performance of Poly(vinylimidazolium) Membranes and Poly(vinylimidazolium)-lonic Liquid Composite Films, Ind. Eng. Chem. Res. 52 (2012) 1023-1032.

[22] P.T. Nguyen, B.A. Voss, E.F. Wiesenauer, D.L. Gin, R.D. Noble, Physically Gelled Room-Temperature lonic Liquid-Based Composite Membranes for CO2/N2 Separation: Effect of Composition and Thickness on Membrane Properties and Performance, Ind. Eng. Chem. Res. 52 (2012) 8812-8821.

[23] F. Karadas, B. Köz, J. Jacquemin, E. Deniz, D. Rooney, J. Thompson, C.T. Yavuz, M. Khraisheh, S. Aparicio, M. Atihan, High pressure $\mathrm{CO} 2$ absorption studies on imidazolium-based ionic liquids: Experimental and simulation approaches, Fluid Phase Equilib. 351 (2013) 74-86.

[24] J.R. Switzer, A.L. Ethier, K.M. Flack, E.J. Biddinger, L. Gelbaum, P. Pollet, C.A. Eckert, C.L. Liotta, Reversible lonic Liquid Stabilized Carbamic Acids: A Pathway Toward Enhanced CO2 Capture, Ind. Eng. Chem. Res. 52 (2013) 13159-13163. 
[25] C.V. Manohar, T. Banerjee, K. Mohanty, Co-solvent effects for aromatic extraction with ionic liquids, J. Mol. Liq. 180 (2013) 145-153.

[26] S.E. Rock, L. Wu, D.J. Crain, S. Krishnan, D. Roy, Interfacial Characteristics of a PEGylated Imidazolium Bistriflamide Ionic Liquid Electrolyte at a Lithium Ion Battery Cathode of LiMn2O4, ACS Appl. Mater. Interfaces 5 (2013) 2075-2084.

[27] M. Egashira, S. Okada, J.-i. Yamaki, D.A. Dri, F. Bonadies, B. Scrosati, The preparation of quaternary ammonium-based ionic liquid containing a cyano group and its properties in a lithium battery electrolyte, J. Power Sources 138 (2004) 240-244.

[28] S. Schaltin, L. D'Urzo, Q. Zhao, A. Vantomme, H. Plank, G. Kothleitner, C. Gspan, K. Binnemans, J. Fransaer, Direct electroplating of copper on tantalum from ionic liquids in high vacuum: origin of the tantalum oxide layer, Phys. Chem. Chem. Phys. 14 (2012) 13624-13629.

[29] A.P. Abbott, G. Frisch, K.S. Ryder, Electroplating Using lonic Liquids, Annu. Rev. Mater. Res. 43 (2013) 335-358.

[30] M.H. Luke, P.F. Matthew, E.K. Brown, M.F. Douglas, C.D.L. Hugh, C.T. Paul, Natural Fiber Welding: lonic Liquid Facilitated Biopolymer Mobilization and Reorganization, Ionic Liquids: Science and Applications, American Chemical Society, 2012, pp. 145-166.

[31] P.K. Singh, B. Bhattacharya, R.K. Nagarale, K.-W. Kim, H.-W. Rhee, Synthesis, characterization and application of biopolymer-ionic liquid composite membranes, Synth. Met. 160 (2010) 139-142.

[32] E. Frackowiak, G. Lota, J. Pernak, Room-temperature phosphonium ionic liquids for supercapacitor application, Appl. Phys. Lett. 86 (2005) 1-3.

[33] X. Zhu, Y. Gao, L. Zhang, H. Li, Prediction among spectra data of 1H NMR, Raman and IR in aqueous solutions of ionic liquid, J. Mol. Liq. 190 (2014) 174-177.

[34] X. Li, Z. Zeng, S. Garg, B. Twamley, J.n.M. Shreeve, Fluorine-Containing lonic Liquids from N-Alkylpyrrolidine and NMethylpiperidine and Fluorinated Acetylacetones: Low Melting Points and Low Viscosities, Eur. J. Inorg. Chem. 2008 (2008) 3353-3358.

[35] S. Zahn, M. Brehm, M. Brüssel, O. Hollóczki, M. Kohagen, S. Lehmann, F. Malberg, A.S. Pensado, M. Schöppke, H. Weber, B. Kirchner, Understanding ionic liquids from theoretical methods, J. Mol. Liq. 192 (2014) 71-76.

[36] N. Khupse, A. Kumar, Dramatic Change in Viscosities of Pure Ionic Liquids upon Addition of Molecular Solvents, J. Solution Chem. 38 (2009) 589-600.

[37] H. Xue, J.n.M. Shreeve, Ionic Liquids with Fluorine-Containing Cations, Eur. J. Inorg. Chem. 2005 (2005) $2573-2580$.

[38] Z.B. Zhou, H. Matsumoto, K. Tatsumi, Low-melting, low-viscous, hydrophobic ionic liquids: N-alkyl(alkyl ether)-Nmethylpyrrolidinium perfluoroethyltrifluoroborate, Chem. Lett. 33 (2004) 1636-1637.

[39] Y. Chen, Y. Cao, X. Sun, T. Mu, Hydrogen bonding interaction between acetate-based ionic liquid 1-ethyl-3methylimidazolium acetate and common solvents, J. Mol. Liq. 190 (2014) 151-158.

[40] A.P. Abbott, Application of hole theory to the viscosity of ionic and molecular liquids, Chemphyschem 5 (2004) 1242-1246.

[41] I. Bandrés, R. Alcalde, C. Lafuente, M. Atilhan, S. Aparicio, On the viscosity of pyridinium based ionic liquids: an experimental and computational study, J. Phys. Chem. B 115 (2011) 12499-12513.

[42] I. Krossing;, J.M. Slattery, Semi-Empirical Methods to Predict the Physical Properties of lonic Liquids: An Overview of Recent Developments, Z. Phys. Chem. 220 (2006) 1343-1359.

[43] J.M. Slattery, C. Daguenet, P.J. Dyson, T.J.S. Schubert, I. Krossing, How to Predict the Physical Properties of lonic Liquids: A Volume-Based Approach, Angew. Chem. Int. Ed. 46 (2007) 5384-5388.

[44] W. Beichel, Y. Yu, G. Dlubek, R. Krause-Rehberg, J. Pionteck, D. Pfefferkorn, S. Bulut, D. Bejan, C. Friedrich, I. Krossing, Free volume in ionic liquids: a connection of experimentally accessible observables from PALS and PVT experiments with the molecular structure from XRD data, Phys. Chem. Chem. Phys. 15 (2013) 8821-8830.

[45] Y. Yu, W. Beichel, G. Dlubek, R. Krause-Rehberg, M. Paluch, J. Pionteck, D. Pfefferkorn, S. Bulut, C. Friedrich, N. Pogodina, I. Krossing, Free volume and phase transitions of 1-butyl-3-methylimidazolium based ionic liquids from positron lifetime spectroscopy, Phys. Chem. Chem. Phys. 14 (2012) 6856-6868.

[46] P. Eiden, S. Bulut, T. Köchner, C. Friedrich, T. Schubert, I. Krossing, In Silico Predictions of the Temperature-Dependent Viscosities and Electrical Conductivities of Functionalized and Nonfunctionalized Ionic Liquids, J. Phys. Chem. B 115 (2011) $300-$ 309.

[47] M.J. Frisch, G.W. Trucks, H.B. Schlegel, G.E. Scuseria, M.A. Robb, J.R. Cheeseman, G. Scalmani, V. Barone, B. Mennucci, G.A. Petersson, H. Nakatsuji, M. Caricato, X. Li, H.P. Hratchian, A.F. Izmaylov, J. Bloino, G. Zheng, J.L. Sonnenberg, M. Hada, M. Ehara, K. Toyota, R. Fukuda, J. Hasegawa, M. Ishida, T. Nakajima, Y. Honda, O. Kitao, H. Nakai, T. Vreven, J.A. Montgomery Jr., J.E. Peralta, F. Ogliaro, M.J. Bearpark, J. Heyd, E.N. Brothers, K.N. Kudin, V.N. Staroverov, R. Kobayashi, J. Normand, K. Raghavachari, A.P. Rendell, J.C. Burant, S.S. Iyengar, J. Tomasi, M. Cossi, N. Rega, N.J. Millam, M. Klene, J.E. Knox, J.B. Cross, V. Bakken, C. Adamo, J. Jaramillo, R. Gomperts, R.E. Stratmann, O. Yazyev, A.J. Austin, R. Cammi, C. Pomelli, J.W. Ochterski, R.L. Martin, K. Morokuma, V.G. Zakrzewski, G.A. Voth, P. Salvador, J.J. Dannenberg, S. Dapprich, A.D. Daniels, Ö. Farkas, J.B. Foresman, J.V. Ortiz, J. Cioslowski, D.J. Fox, Gaussian 09, Gaussian, Inc., Wallingford, CT, USA, 2009. 
[48] S. Bulut, P. Eiden, W. Beichel, J.M. Slattery, T.F. Beyersdorff, T.J.S. Schubert, I. Krossing, Temperature Dependence of the Viscosity and Conductivity of Mildly Functionalized and Non-Functionalized [Tf2N]- Ionic Liquids, Chemphyschem 12 (2011) 2296-2310.

[49] R.L. Gardas, J.A.P. Coutinho, A group contribution method for viscosity estimation of ionic liquids, Fluid Phase Equilib. 266 (2008) 195-201.

[50] R.C. Reid, J.M. Prausnitz, B.E. Poling, The Properties of Gases and Liquids, McGraw-Hill, USA, 1987.

[51] S. Aparicio, M. Atilhan, F. Karadas, Thermophysical properties of pure ionic liquids: Review of present situation, Ind. Eng. Chem. Res. 49 (2010) 9580-9595.

[52] R.L. Gardas, J.A. Coutinho, Group contribution methods for the prediction of thermophysical and transport properties of ionic liquids, AIChE J. 55 (2009) 1274-1290.

[53] H. Yamamoto, Structure Properties Relationship of Ionic Liquid, J. Comput. Aided Mol. Chem. 7 (2006) 18-30.

[54] H. Matsuda, H. Yamamoto, K. Kurihara, K. Tochigi, Computer-aided reverse design for ionic liquids by QSPR using descriptors of group contribution type for ionic conductivities and viscosities, Fluid Phase Equilib. 261 (2007) 434-443.

[55] K. Tochigi, H. Yamamoto, Estimation of Ionic Conductivity and Viscosity of Ionic Liquids Using a QSPR Model†, J. Phys. Chem. C 111 (2007) 15989-15994.

[56] R. Bini, M. Malvaldi, W.R. Pitner, C. Chiappe, QSPR correlation for conductivities and viscosities of low-temperature melting ionic liquids, J. Phys. Org. Chem. 21 (2008) 622-629.

[57] F. Gharagheizi, P. Ilani-Kashkouli, A.H. Mohammadi, D. Ramjugernath, D. Richon, Development of a group contribution method for determination of viscosity of ionic liquids at atmospheric pressure, Chem. Eng. Sci. 80 (2012) 326-333.

[58] J. Valderrama, J. Muñoz, R. Rojas, Viscosity of ionic liquids using the concept of mass connectivity and artificial neural networks, Korean J. Chem. Eng. 28 (2011) 1451-1457.

[59] I. Billard, G. Marcou, A. Ouadi, A. Varnek, In Silico Design of New lonic Liquids Based on Quantitative Structure-Property Relationship Models of Ionic Liquid Viscosity, J. Phys. Chem. B 115 (2010) 93-98.

[60] K.R. Seddon, A. Stark, M.-J. Torres, Influence of chloride, water, and organic solvents on the physical properties of ionic liquids, Pure Appl. Chem. 72 (2000) 2275-2287.

[61] M. Frenkel, R.D. Chirico, V. Diky, C.D. Muzny, A.F. Kazakov, J.W. Magee, I.M. Abdulagatov, K. Kroenlein, C.A. Diaz-Tovar, J.W. Kang, R. Gani, ThermoData Engine, NIST Standard Reference Database \#103b (Pure Compounds, Binary Mixtures, and Chemical Reactions), version 7.0, National Institute of Standards and Technology, Gaithersburg, MD 20899, USA, http://www.nist.gov/srd/nist103b.cfm, 2011.

[62] S. Zhang, X. Lu, Q. Zhou, X. Li, X. Zhang, S. Li, lonic Liquids:: Physicochemical Properties, Elsevier Science, Hungary, 2009.

[63] U.P.R.M. Preiss, J.M. Slattery, I. Krossing, In Silico Prediction of Molecular Volumes, Heat Capacities, and TemperatureDependent Densities of Ionic Liquids, Ind. Eng. Chem. Res. 48 (2009) 2290-2296.

[64] A. Ouadi, B. Gadenne, P. Hesemann, J.J.E. Moreau, I. Billard, C. Gaillard, S. Mekki, G. Moutiers, Task-Specific lonic Liquids Bearing 2-Hydroxybenzylamine Units: Synthesis and Americium-Extraction Studies, Chem. Eur. J. 12 (2006) 3074-3081.

[65] M. Sattari, F. Gharagheizi, P. Ilani-Kashkouli, A.H. Mohammadi, D. Ramjugernath, Estimation of the Heat Capacity of lonic Liquids: A Quantitative Structure-Property RelationshipApproach, Ind. Eng. Chem. Res. 52 (2013) 13217-13221.

[66] M. Sattari, F. Gharagheizi, P. Ilani-Kashkouli, A. Mohammadi, D. Ramjugernath, Development of a group contribution method for the estimation of heat capacities of ionic liquids, J. Therm. Anal. Calorim. 115 (2014) 1863-1882.

[67] J. Marrero, R. Gani, Group-contribution based estimation of pure component properties, Fluid Phase Equilibria 183 (2001) 183-208.

[68] W.T. Laughlin, D.R. Uhlmann, Viscous flow in simple organic liquids, J. Phys. Chem. 76 (1972) 2317-2325.

[69] F. Endres, D. MacFarlane, A. Abbott, Electrodeposition from Ionic Liquids, Wiley, 2008. 


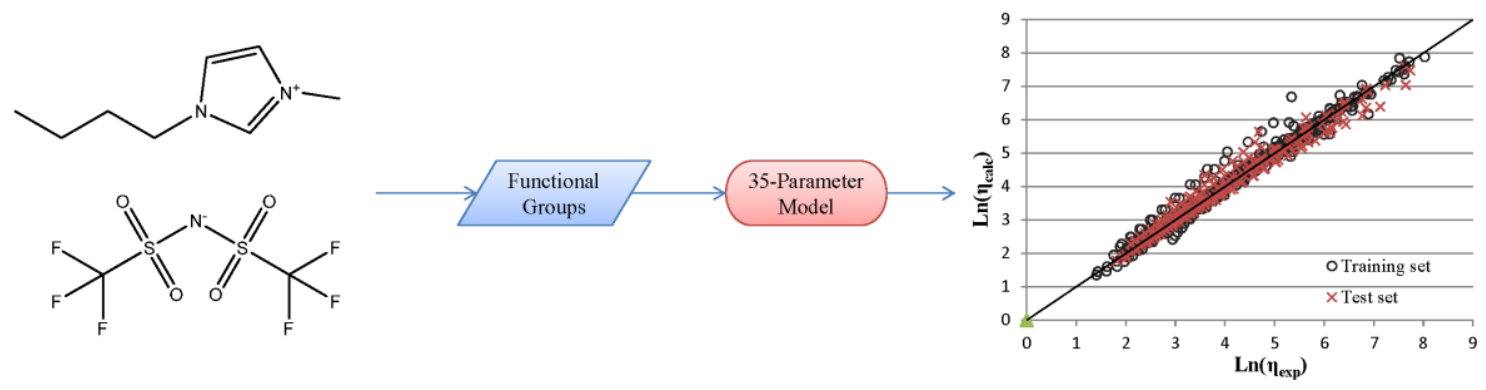

